\title{
MICROSTRUCTURAL CHARACTERIZATION OF CAST 718
}

R.G. Carlson, GE Aircraft Engines, Evendale, ohio and J.F. Radavich, Purdue University, west Lafayette, Indiana.

\section{ABSTRACT}

A detailed investigation of cast IN 718 was conducted on phases formed during solidification, phases precipitated on cooling and phase stability. Clearly cast 718 is a composite structure. Extensive as-cast segregation is evident which shows a low $\mathrm{Cb}$ content, about $2 \%$, in the dendritic matrix, and a high $\mathrm{Cb}$ content, about $10 \%$ in the interdendritic region. Homogenization studies show that Laves solutioning does not uniformly redistribute the $\mathrm{Cb}$. This work also indicates that the standard GE homogenization heat treatment of $2000^{\circ} \mathrm{F} / 1$ hour dissolves most of the delta and a portion of the Laves. Depending on the $\mathrm{Cb}$ content in the alloy, total Laves solutioning requires at least 3 hours at $2100^{\circ} \mathrm{F}$, but a more uniform $\mathrm{Cb}$ distribution requires 100 hours or more beyond the standard heating cycle. The results of this investigation may serve as a guide in microstructural interpretation and can offer a viable explanation for the variability of mechanical properties on bars extracted from castings. 
INTRODUCTION

Cast 718 continues to gain applications in aircraft engines for compressor and turbine frames, combustor cases, fuel nozzle rings and other hot engine structures. The reasons are obvious: cast 718 has good strength, corrosion resistance and ductility, good weldability, along with longtime stability below $1200^{\circ} \mathrm{F}$ and has few critical alloying elements. With the advent of major casting technology improvement, large components of cast 718 have been made cost effective by reducing the time procurement cycle and the number of welding operations to fabricate structural hardware. The mechanical properties of cast 718 have greatly improved from those obtained in the 1960's due to two main reasons: (1) the use of HIPing to close casting porosity and (2) the better understanding of the heat treatments resulting in improved cast 718 microstructures.

As ever higher stresses are imposed on cast 718 , the variables which dictate mechanical properties become more important and need more study. Barker, in 1961, studied the effects of heat treatments on cast $718(1)$ and more recent work by Bouse and Schilke have related properties after various heat treatments with and without HIPing $(2,3)$. Their conclusions showed that grain size, Laves phase, del ta phase, and dendrite arm spacing play an important role in the optimization of the mechanical properties in select heats of cast 718. Bouse and Schilke's work on the effect of Hiping on porosity closure and the homogenization of the Laves phase indicates that property variability occurs when select HIP temperatures and post HIP heat treatments were given.

Because of the many questions still unanswered regarding structural behavior and mechanical properties, a structural characterization study of cast 713 has been undertaken. In this effort, optical microscopy and SEM techniques are used to follow the structural changes when cast 718 is given standard and various other heat treatments. In addition, EDAX type analyses are used to study the chemical changes produced by thermal cycles. 


\section{CONCLUSIONS}

Observations from these studies on cast 718 have helped in refining the understanding of phases initially formed aiong with phases precipitated during cooling and their stability. Clearly, cast 718 is a composite structure with extensive segregation at the interdendritic and the dendritic( $Y$ )

regions. In essence, the $Y$ matrix is reinforced by the more highly alloyed, Laves and MC laced, interdendritic region.

1. Extensive segregation in as-cast $\pi 8$ is observed. The interdendritic phases consist primarily of Laves and MC. However, as the casting cools, both $C b$ enriched delta and $Y^{*}$ precipitate in this interdendritic region. Large cast sections cool slowly and produce increased amounts of del ta and $Y^{*}$, which further highlight segregation. Porosity also is found in the interdendritic regions and is predominately associated with Laves islands.

2. $C b$ is the key element in achieving chemical, physical and mechanical property uniformity. It appears that cast 718 alloy with greater than $5 \%$ $\mathrm{Cb}$ will require extended homogenization treatments, while alloys with about $4 \% \mathrm{Cb}$ can more readily be homogenized. Chemical analysis of the as-cast 718 show a low $C b$ content, about $2 \%$, in the dendritic matrix, and a high cb content, about 10\%, in the interdendritic region. The waximum improved homogenization treatment could not level out this segregation.

3. The uniform precipitation of fine $Y^{\prime} / Y^{\prime \prime}$ phases necessary for maximum mechanical properties, requires solutioning of the laves phase along with Cb interdiffusion. Homogenization studies show that Laves solutioning does not fully redistribute $\mathrm{Cb}$. The standard homogenization heat treatment of $2000^{\circ} \mathrm{F} / \mathrm{h}$ hour dissolves most of the del ta and a portion of the Laves. Total solutioning of the Laves requires at least 3 hours at $2100^{\circ} \mathrm{F}$, but a more uniform $\mathrm{Cb}$ distribution requires additional time of 10 hours or more, after the standard HIP cycle. It is quite likely that total homogenization can not be achleved with current economic constraints. A further example of this $c b$ segregation effect and non uniform precipitation was noted on a previous study.

4. The application of a HIP cycle, or similar high temperature treatments, produces sub boundaries outlining domains within the segregation area. The $Y^{\prime \prime}$ phase appears to precipitate within these boundaries during cooling and/or subsequent heat treatment. The significance of these sub-boundaries is not understood at this time.

5. The $1600^{\circ} \mathrm{F}$ "Tag" treatment was very successful in delineating the $\mathrm{Cb}$ segregation. "Tag" treatments of greater than one hour should be avoided as the $Y^{\prime \prime}$ to delta transformation occurs rapidiy in high $C b$ areas, and non-reproductble results can occur. 
Phase Review - Alloy 718

Al though many structural studies have been carried out on wrought 718 and on powder 718, a brief review of the phases in cast 718 is useful in understanding the structural results found in this study.

Cast superalloys show a similar behavior during solfdification in that the $Y$ solid rejects those elements which have a larger atomic diameter than the $N$ i base- namely, $\mathrm{II}, \mathrm{Al}, \mathrm{MO}_{0}$, and $\mathrm{Cb}$. The longer the solidification process takes, the more the segregation is evident. Thus, section sizes which are large will cool slower than thin sections and greater segregation will result. Similar solidification behavior will be shown by the fast cooling ingot edge as compared to the slower cooled ingot center. The rejected elements locate in the interdendritic regions and the phases formed in these areas are comprised of these elements, i.e. carbides, borides, Laves phase, etc. Phases wich thus form in the interdendritic areas must be solutioned, if possible, in order to honogenize the chemistry for subsequent optimum phase precipitation.

Cast 78 is similar to other cast alloys in that selective elements are rejected during solidification-Ti, Al, Mo, and $\mathrm{Cb}$. The initial phase present after the $Y$ phase nucleates is the $C b, T 1$ primary carbides. The shape, size and amount of the primary carbides depend on the chemistry, along with solidification conditions. Al though this primary carbide wich contains mostly $C D$ with some $T i$ is scattered throughout the matrix, it is more abundant in the $c b$ rich interdendritic regions. In these same $c b$ rich areas, the $c b$ rich Laves phase forms in amounts and size dependent on the $\mathrm{Cb}$ content and the cooling rate. As the alloy cools to lower temperatures, a needle-like phase called the delta phase (orthorhombic $\mathrm{Ni}_{3} \mathrm{Cb}$ ) forms close to or attached to the Laves phase. Additional cooling will result in smaller plate-like structures fomation and these phases are the $Y^{\prime \prime}$ and $Y^{\prime}$ phases.

Typical microstructures of as-cast 718 are shown in Figure 1. In Figure 1, the dark areas or 1 slands are Laves phase, the mite discrete particles are the $M C$ phase, and the plate structure is the $\mathrm{Ni}_{3} \mathrm{Cb}$ (delta) phase.

\section{Heat Treatments}

A number of heat treatments were carried out to determine wich variables such as time, temperature, cooling rate, and cb distribution were critical in the homogenization and the precipitation of the strengthening $Y^{\prime}$ and/or $Y^{\prime \prime}$ phases. 

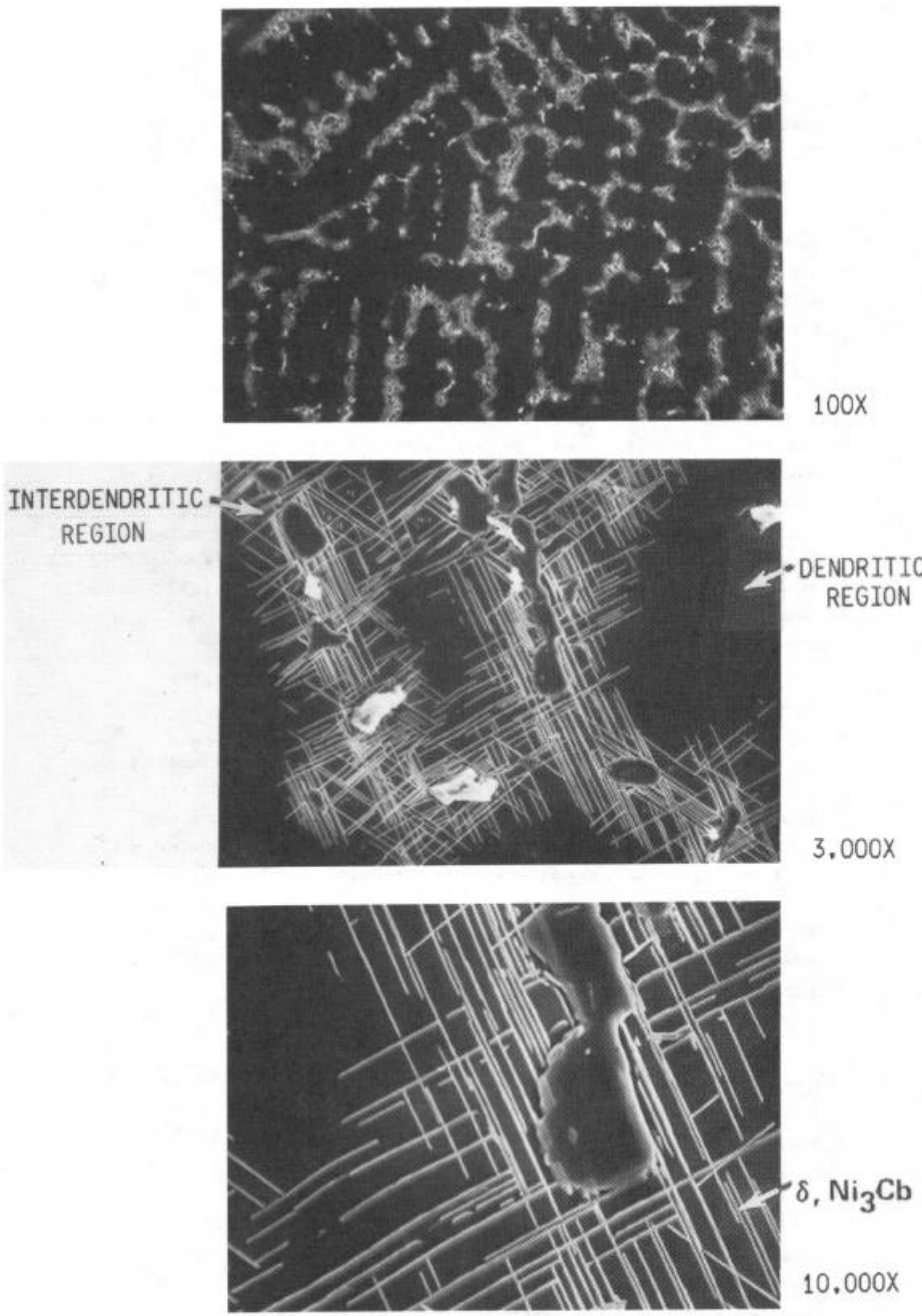

FIGURE 1: TYPICAL SEM, MICROSTRUCTURE OF AS-CAST 718 
While no mechanical properties were to be deterwined in this study, the materials used in this investigation were previousiy tested in the as-cast and heat treat $\left(^{*}\right)$ condition with a rupture life of over 20 hours at $1200^{\circ} \mathrm{F}$ and 90 KSI stress. However, other cast 718 material similar to the cast material in this study had shown large variations in stress rupture properties and it is belleved that such variabllity could be explained fron results of this investigation. The in-depth microstructural study involved both optical and scanning electron microscope techniques for phase characterization and $x$-ray diffraction and EDAX analyses for phase identification and chemical composition.

A Temperature-Phase Stability diagram for the structures in alloy 718 is given in Figure 2. The range of the temperatures in mich the various phases can be found is only valid if the cast material has been originally homogenized and then heat treated. A pseudo $\pi T$ diagram for del ta and $Y^{\prime \prime}$ after annealing in the $1200-2000^{\circ} \mathrm{F}$ temperature range for alloy 78 is shown in Figure 3. The temperature ranges of phase precipitation change as the chemistries vary and/or If the material initially is not totally homogenized as evident in the interdendritic ( $h$ igh $\mathrm{Cb}$ ) or the dendritic (low $\mathrm{Cb}$ ) structures. Hence, no single $I T$ diagram can be obtained for a cast, nonhomogeneous structure.

\section{METALLOGRAPHIC TECHNIQUES FOR CAST 718}

Since particle sizes and standard structures vary widely in castings, both the optical and scanning electron microscope are needed to characterize the structures. The metallographic techniques described in literature vary greatly because in most cases the samples are prepared by a mechanical polish and etch. It has been the experience in Micro-Het that distinct phases in alloy 718 are difficult to detect by standard preparation procedures as varied themal treatments cause the material to etch differently. Electrolytic polishing and etching yield more reproductble results and extremely fine $\gamma^{\prime}$ and $Y^{\prime \prime}$ structures can be detected.

The segregation patterns when viewed optically show a brownish or darkened area; however, on the SEM, these areas show bright secondaries due to the high $\mathrm{cb}$ content. Thus, the extent of the segregation can be checked by both microscopes, but with greater resolution and more certainty by the SEM.

\footnotetext{
* Heat treatment consisted of $2000^{\circ} \mathrm{F} / \mathrm{hr}$, Air Cool $+1750^{\circ} \mathrm{F} / \mathrm{hr}$, Air Cool + $1325^{\circ} \mathrm{F} / 8 \mathrm{hrs}$, Furnace Cool $100^{\circ} \mathrm{F} / \mathrm{hr}$ to $1150^{\circ} \mathrm{F} / 8 \mathrm{hrs}$, Air Cool

(in a suitabie protective atmosphere).
} 


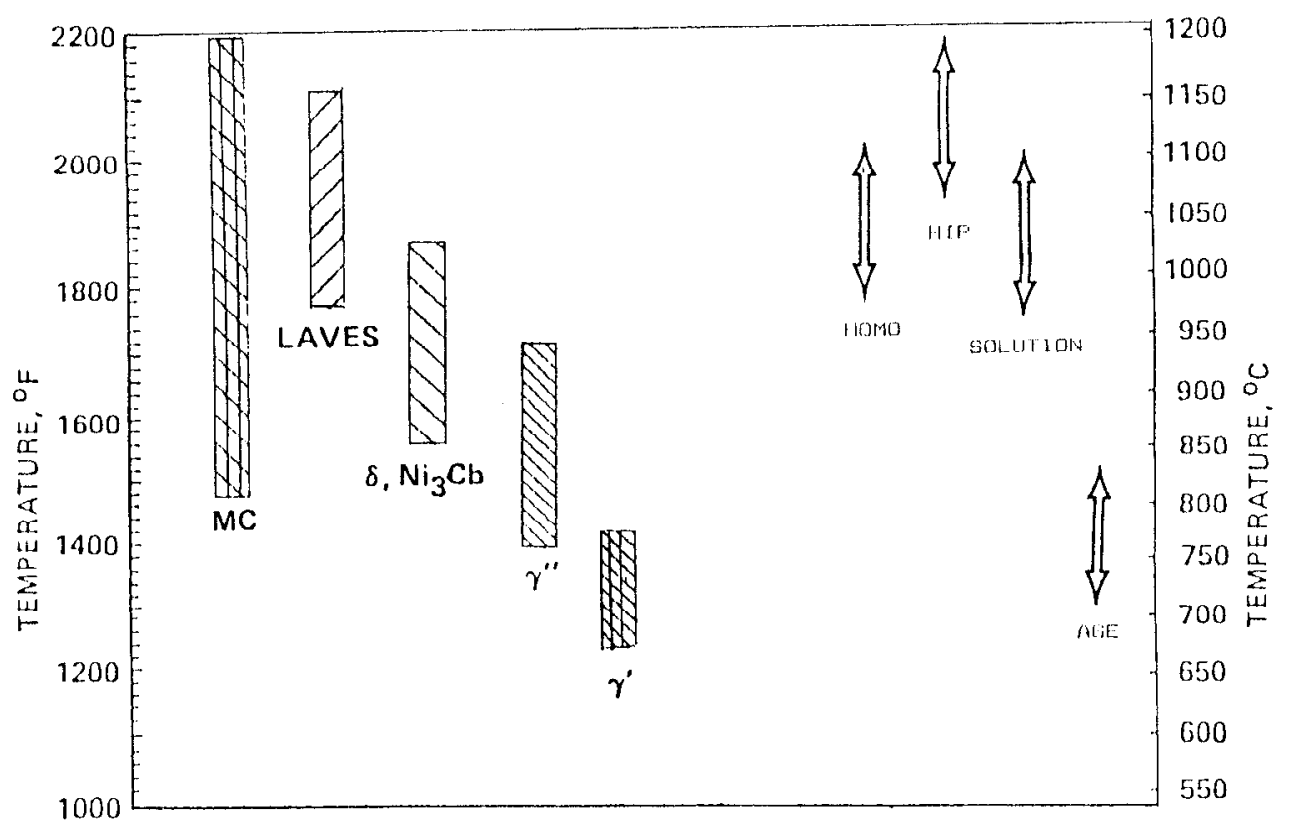

FIGURE 2: TEMPERATURE-PHASE STABILITY DIAGRAM FOR CAST 718 ALONG WITH TEMPERATURE FOR HOMOGFNTZATION AND HIP HEAT TREAT CYCLE

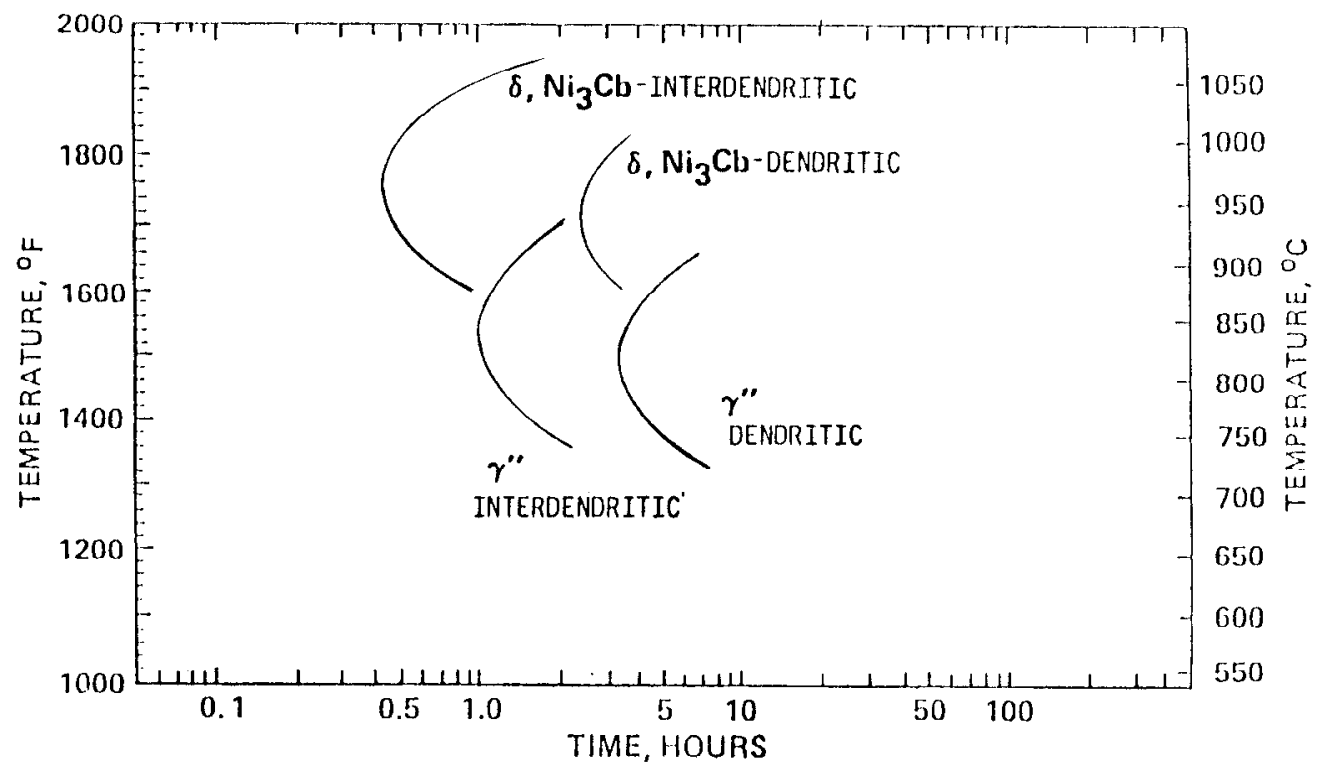

FIGURE 3: TIME-TEMPERATURE TRANSFORMATION DIAGRAM FOR ALLOY 718 
Previous studies of the same heat of cast 78 at Micro-Het Labs has shown that the needle-like $\mathrm{NI}_{3} \mathrm{Cb}$ (delta) phase plates growing from the Laves phase can be solutioned after 10 hours at $1900^{\circ} \mathrm{F}$ or 2 hours at $2000^{\circ} \mathrm{F}$. No del ta phase was found at $2050^{\circ} \mathrm{F}$ or higher. However, the Laves phase is more resistant to solutioning requiring 20 hours at $2000^{\circ} \mathrm{F}, 10$ hours at $2050^{\circ} \mathrm{F}, 4$ hours at $2100^{\circ} \mathrm{F}$, or $1-2$ hours at $2150^{\circ} \mathrm{F}$. Solution studies at $2150^{\circ} \mathrm{F}$ showed erratic behavior of phase solutioning as incipient melting was observed in short times but not detected in longer exposure times.

The MC phase is present after all solutioning times but whether the amount of the MC has decreased or the morphology al tered with increasingly higher solution temperatures could not be determined.

The results of the study at Micro-Het Labs show only the time at temperature needed to solution the various phases in the as-cast 78 . The distribution of the elements, especially $\mathrm{Cb}$, from the dissolution of the Laves and del ta phases must be determined by either chemical analysis or by thermaliy treating the samples at temperatures wich cause $\infty \mathrm{rich}$ precipitation to occur in regions of high $\mathrm{Cb}$ content. Such a technique for detection of $\mathrm{Cb}$ distribution is called a "Tag" heat treatment and is described next.

\section{CAST 78 "TAG" HEAT TREATMENT}

Previous studies on cast 78 have shown that the most consistent and reproducible precipitation phase wich is associated with $C b$ enriched areas is the $\gamma^{*}$ phase. This phase precipitates in a wide temperature range. When formed at about $1600^{\circ} \mathrm{F}$, the $\gamma^{\prime \prime}$ precipitate can be easily detected with the SEM. The $Y^{\prime}$ phase does not lend itself to be used as a measure of $C b$ distribution since it precipitates at lower temperatures in longer times and is primarily $\mathrm{Ni}_{3} \mathrm{Al}$. The small amount of $\mathrm{Cb} \mathrm{Y}^{\prime}$ which is involved in the precipitation does not readily differentiate $c b$ enriched areas.

The "Tag" heat treatment used throughout this study was a one hour exposure at $1600^{\circ} \mathrm{F}$. X-ray analyses of extracted residues as well as metallographic etching behavior confimed the "Tag" precipitate to be the $Y$ ". CHEMICAL SEGREGATION AND METALLOGRAPHIC RESULTS

The as-received cast 718 materials from different vendors and heats of material can show different microstructures. Some as-cast 718 materials show large plates of delta phase wile other cast material shows predoninately small plates of $Y^{\prime \prime}$.

The differences in

the segregation phases may be attributed to the cooling rate through the delta and $Y^{*}$ temperature ranges, along with the amount of $c b$ in the heat. Thicker sections show evidence of greater segregation. EDAX analysis delineates this segregation. 


\section{EONX AMALYSES}

EDAX analyses of the as-cast condition of the dark areas and those areas wich appear wite show a monotonic increase of $C b$ content from the dendrite into the interdendritic segregation zone. Typical results are given in Figure 4 for this chemical distribution.

\section{CAS'T 718 EDAX: AS-CAS'I}



FIGURE 4: EDAX ANALYSIS OF DENORITIC AND INTERDENDRITIC REGIONS OF AS-CAST 718

It is apparent that the segregation areas of the interdendritic region are enriched in $\mathrm{Cb}, \mathrm{Tt}$ and Mo but lower in $\mathrm{Fe}$ and $\mathrm{Cr}$. The chemical analyses at the segregation areas must be viewed with caution as the segregation may extend beneath the probe spot and give higher readings. In situ chemical analyses of the small MCs and Laves Islands should al so be questioned since the matrix may be excited by the beam. Generally, the best analytical technique for carbide and Laves phase analyses is by analyzing extracted residues. $X$-ray analyses can also be carried out on the extracted residues and correlated with the chemical analyses of the extracted residues.

\section{Typlcal structures of as-cast are shown in Figure 5 .}

The foregoing discussion of as-cast materials showed that the dffferences in segregation resulted in variable of precipitation of $Y^{\prime \prime}$ and delta phases during the cooling of the material. When cast 718 materials are subjected to high thermal treatments such as homogenization, HIPing, etc., the resultant microstructures can be drastically altered. The structural results of various thermal treatments follow. 
HOMOGENIZATION - 1 HOUR AT $2000^{\circ} \mathrm{F}$

The as-cast materials which were given a 1 hour $2000^{\circ} \mathrm{F}$

homogenization cycle, showed that the as-cast smaller $\gamma^{\prime \prime}$ plates had been solutioned and only small amounts of the delta phase with the Laves islands remain. Figure 6 showstypical structures present. Optical metallography with the $2000^{\circ} \mathrm{F} n$ hour treatment is shown in Figure 7 . Here, littie evidence is noted of the del ta phase. However, in the cooling from the $2000^{\circ} \mathrm{F}$ temperature, a fine precipltation was detected by SEM in both materials and identified as $Y^{\prime \prime}$. From other studies of cast 718 wich were treated for 1 hour at $2000^{\circ} \mathrm{F}$, water quenched and isothermaliy aged, the $\gamma^{\prime \prime}$ phase appeared only when the isothemal temperature was $1700^{\circ} \mathrm{F}$ or below. The appearance of the $\gamma^{\prime \prime}$ in the $2000^{\circ} \mathrm{F} /$ hour sample undoubtedly occurred during the cooling through the temperature range of $1700^{\circ} \mathrm{F}$ to $1400^{\circ} \mathrm{F}$.

EDAX analysis was carried out on the "homogenized" material to determine the changes of chemistry brought about by the 1 hour at $2000^{\circ} \mathrm{F}$. Al though the reported EDAX chemistry levels are valid, these levels are prone to variations due to impingement angles, chemistry compositions, and surface conditions.

The relative chemistry levels are real. Areas similar to the as-cast material areas were EDAX analyzed and the results are shown in figure 8 .

Here it can be noted that the co content increased in the dendritic region to above $3 \%$ from about $2 \%$ in as-cast-state, while co content decreased in the center interdendritic region to about $8 \%$ from about $10 \%$ in as-cast-state. Again these results show high degree of segregation is still evident in the interdendritic region compared to the dendritic region.

CAS'T 718 EDAX: HOMO(i) 2OOOF $1 \mathrm{HR}$

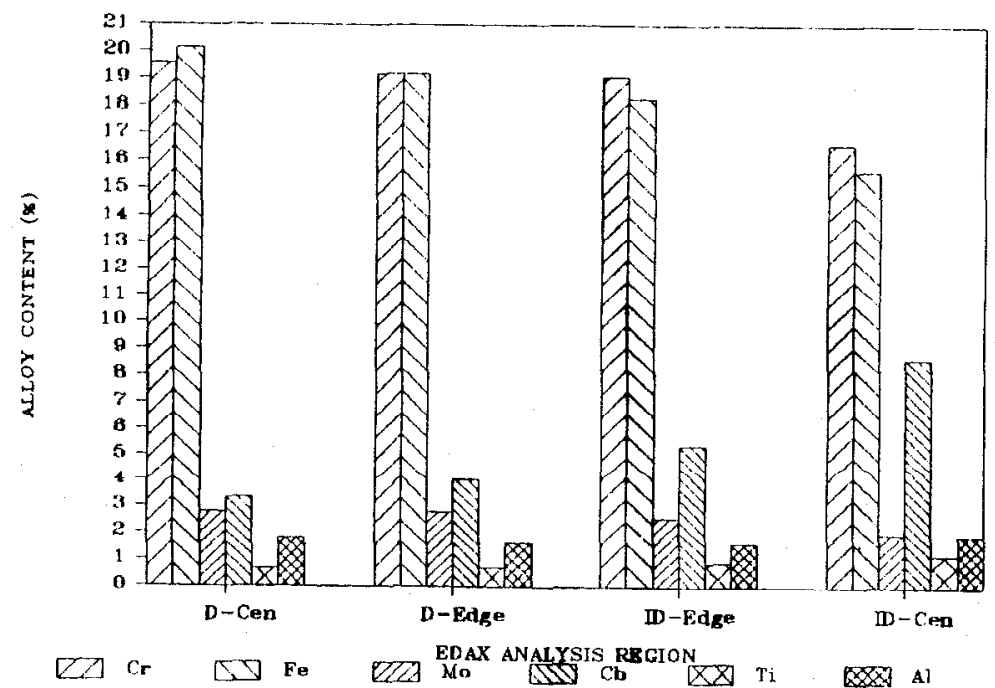

FIGURE 8: EDAX ANALYSIS OF DENDRITIC AND INTEROENDRITIC REGIONS OF CAST 718 WITH $2000^{\circ} \mathrm{F} / 1$ HOUR TREATMENT 




$100 x$

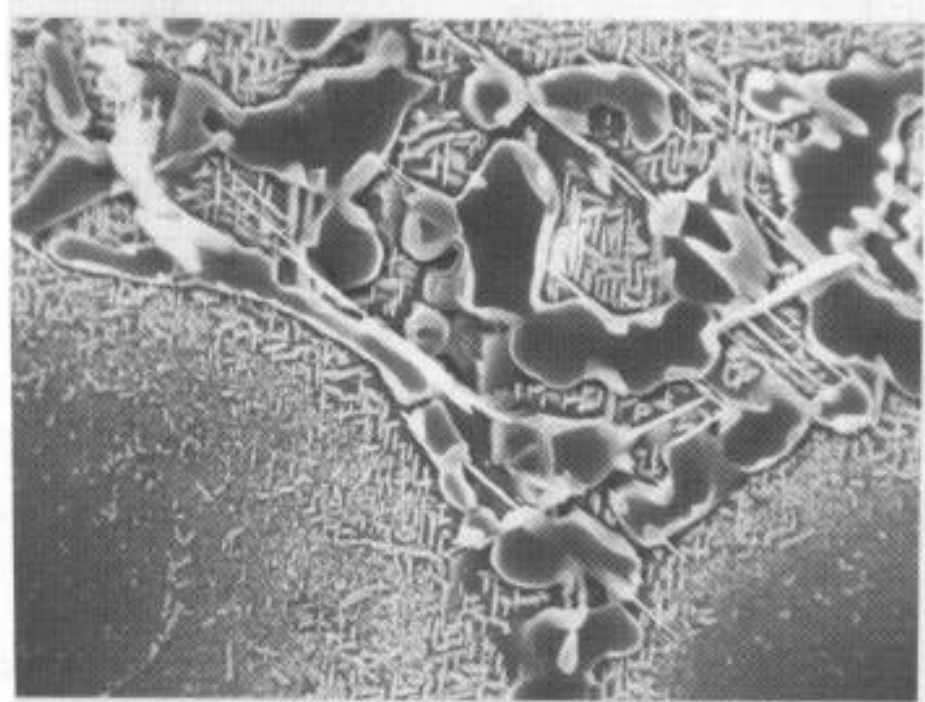

$1.000 x$

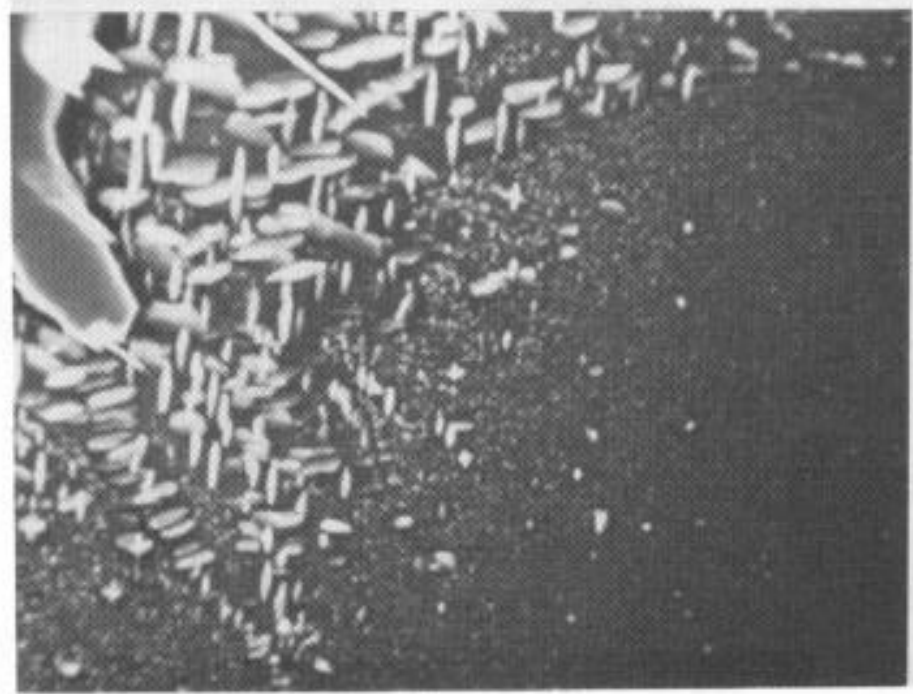

$10,000 x$

FIGURE 5: SEM MICROSTRUCTURE OF AS-CAST 718 


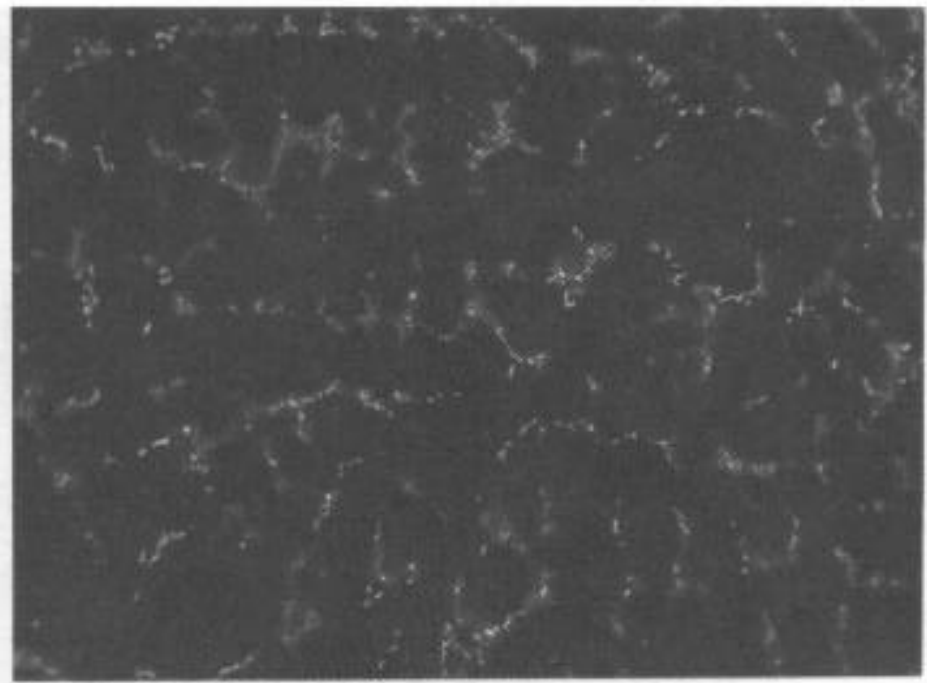

$100 x$

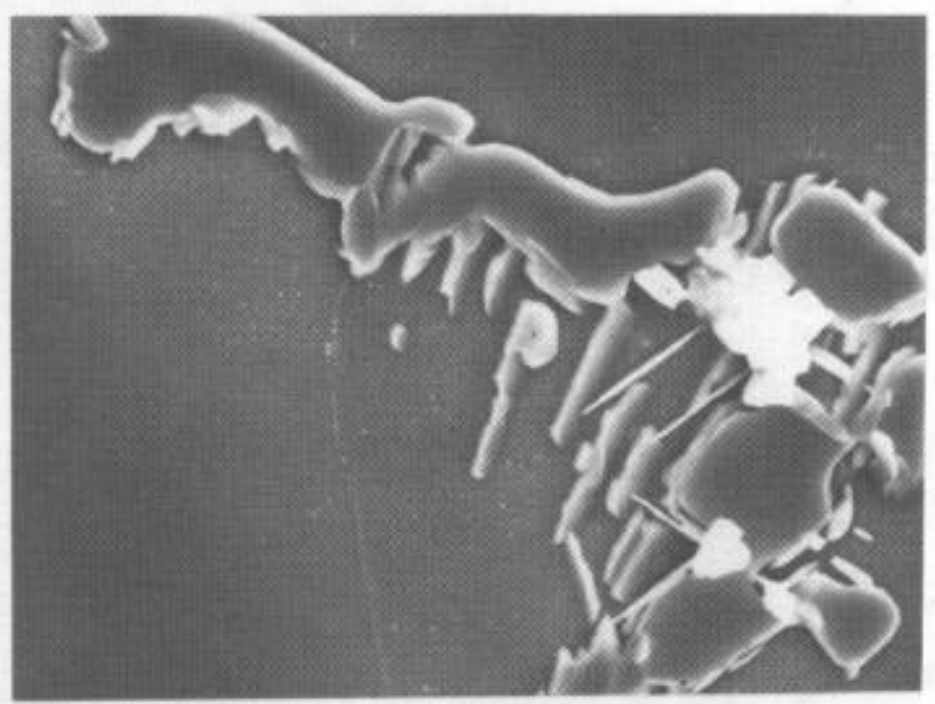

$3.000 x$



$10,000 x$

FIGURE 6: SEM MICROSTRUCTURE OF CAST 718 AFTER $2000^{\circ} \mathrm{F} / 1$ HOUR 


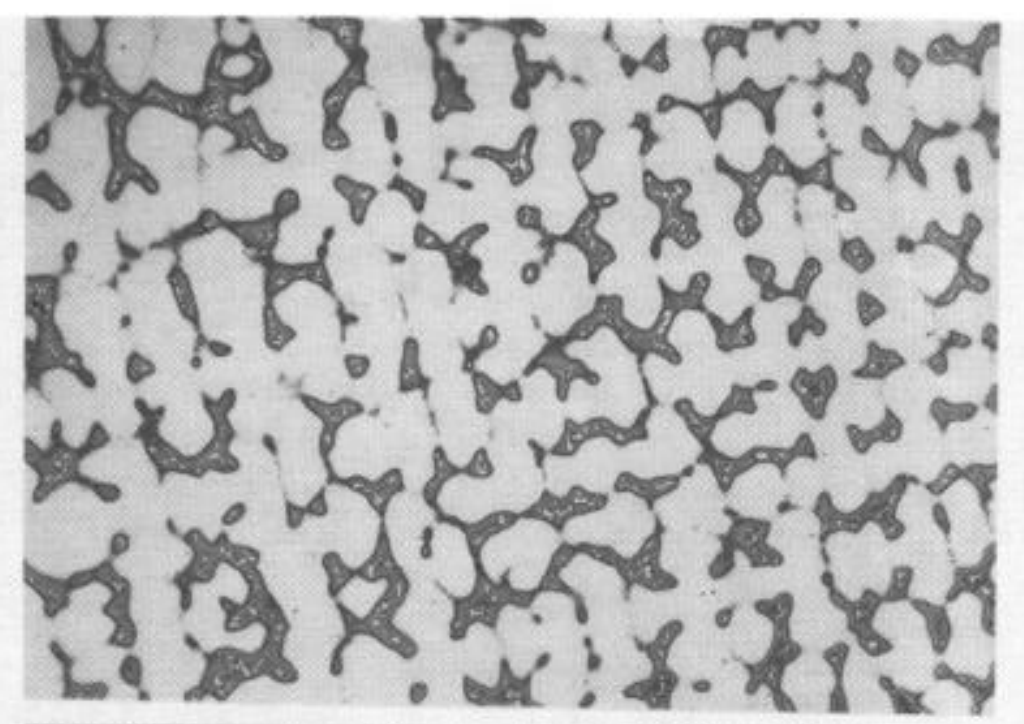

$100 x$

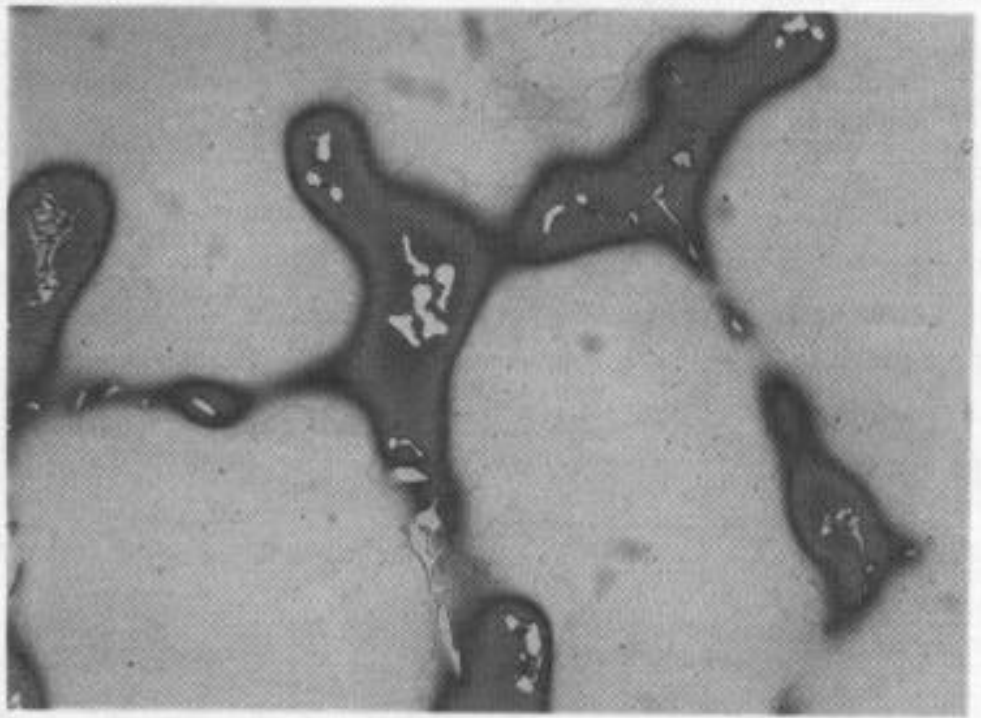

$500 x$

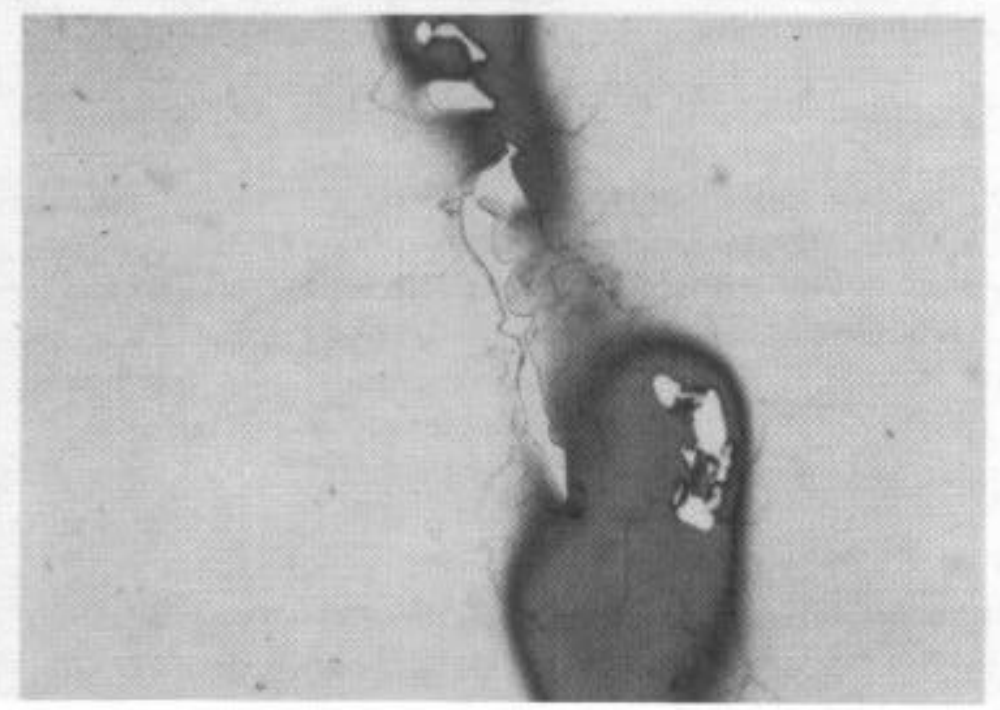

$1.000 x$

FIGURE 7: OPTICAL MICROSTRUCTURE OF CAST 718 AFTER $2000^{\circ} \mathrm{F} / 1$ 
HOMOGENIZED $+2125^{\circ} \mathrm{F} / 4$ HOUR HIP $+2100^{\circ} \mathrm{F} / 8$ HOUR (FURNACE COOLED)

The homogenized material which was given a $2125^{\circ} \mathrm{F} / 14.7 \mathrm{ksi} / 4$ hour HIP treatment and then an 8 hour exposure at $2100^{\circ} \mathrm{F}$ showed a more diffuse nature of the black and white patterns indicating less segregation present. While the MC phase appeared to be the only phase evident at low magnification, a fine precipitation is present in the white areas at high magnification. This precipitation is $Y^{\prime \prime}$. The regions near the grain boundaries showed larger $Y^{\prime \prime}$ particles than those particles in the dendrite remnants. A vein-like or subgrain boundary structure is noticeable in this furnace cooled material. such vein-itke structures are not as noticeable in water quenched material frow the same temperature.

HOMOGENIZED $+2125^{\circ} \mathrm{F} / 4^{\text {HOUR HIP }+1925^{\circ} \mathrm{F} / 1 \text { HOUR (WATER QUENCH) }+1400^{\circ} \mathrm{F} / 5}$ HOURS

The black and wite areas indicate segregation is present, but the degree of segregation appears less than the structure with only the $2000^{\circ} \mathrm{F} / 1$ hour homogenization. The MCs are still detected in the segregated regions, while there is some precipitation of grain boundary particles evident. The $Y^{*}$ phase appears to extend further into the grains. Within the grains many lines or boundarles appear that are decorated with internediate sized precipitates. In the grains a fine precipltate is presan: due to the $1400^{\circ} \mathrm{F} / 5$ hours aging treatment. The amount of precipitation in the grains is not as great as the grain boundary precipitation. The $1400^{\circ} \mathrm{F}$ age gives more microstructural contrast than with a simple solution treatment furnace cool (described next) because the $Y^{\prime \prime}$ precipitation occurs more readily at $1400^{\circ} \mathrm{F} / 5$ hours than the $Y$ which forms only during cooling. However, a larger size component would cool slower than the samples in this study and, therefore, the $Y^{\prime \prime}$ formed during cooling undoubtedly would be larger.

HOMOGENIZED $+2125^{\circ} \mathrm{F} / 4$ HOUR HIP $+1925^{\circ} \mathrm{F} 1$ HOUR (FURHACE COOLH $1400^{\circ} \mathrm{F} / 5$ HOURS

The furnace cool from $1925^{\circ} \mathrm{F}$ results in a decreased contrast between the dark and light areas. This decrease occurs since the $1400^{\circ} \mathrm{F}$ age produces more precipitation in the darker areas and reduces the sharp line of precipitation demarcation. The precipitation found in this sample is similar to that of the sample which was water quenched from $1925^{\circ} \mathrm{F}$, excepting now the $Y^{\prime \prime}$ precipitation and/or grain boundary precipitation is larger This is due to more rapid growth of the nucleated $Y^{\prime \prime}$ precipitation in the transient cooling than a precipitation infch nucleated only at $1400^{\circ} \mathrm{F}$. Vein-like or subgrain type structures are also present in this sample and again the $Y$ precipitation decorating these boundaries is heavier than those in the water quenched sampie. 
The appearance of the fine precipitation of $Y^{\prime \prime}$ in the dark areas or dendritic grains in the cast 718 signiftes either that kinetics for $Y^{\prime \prime}$ formation is different or the amount of $C b$ necessary for precipitation of fine $Y^{*}$ at the lower temperatures is less than precipitation wich forms at $1600^{\circ} \mathrm{F}$. Metallurgically speaking it seems plausible that once the Laves phase is solutioned and the sample receives high temperature homogenization treatments, the $c b$ diffusion should increase and $C b$ rich $Y$ precipitation should be found further into the grains from the boundaries. In the past, the detection of fine precipitation might have been more difficult due to metallographic preparation and resolution problems. Detalled studies of precipitation of fine $Y^{\prime}$ and/or $Y^{\prime \prime}$ at lower aging temperatures of $1200^{\circ} \mathrm{F}$ would necessitate the use of a TEM.

EDAX ANALYSIS OF HOMOGENIZED $+2125^{\circ} \mathrm{F} / 4$ HOUR HIP $+1925^{\circ} \mathrm{F}$ (HATER QUENCH) + $1400^{\circ} \mathrm{F} / 5$ HOURS

The detection of a $Y^{\prime \prime}$ type precipitate in the grain matrix after high temperature thermal treatments shows that co segregation diminishes. The change in cb content frow the original high grain boundary levels can be followed by EDAX analysis. EDAX analysis was carried out on areas representing dendritic and interdendritic locations as performed on as-cast material. The results are seen in Figure 9 .

Here it can be noted that the $c b$ content in the interdendritic region has extensively decreased to levels in the order of 5\%. The level of $c b$ in the dendritic region remains at a relatively low level of about $2 \%$. However, the amount of dendritic area with low $\mathrm{Cb}$ content decreases and conconitantly the amount of interdendritic areas with high $\mathrm{Cb}$ decreases.

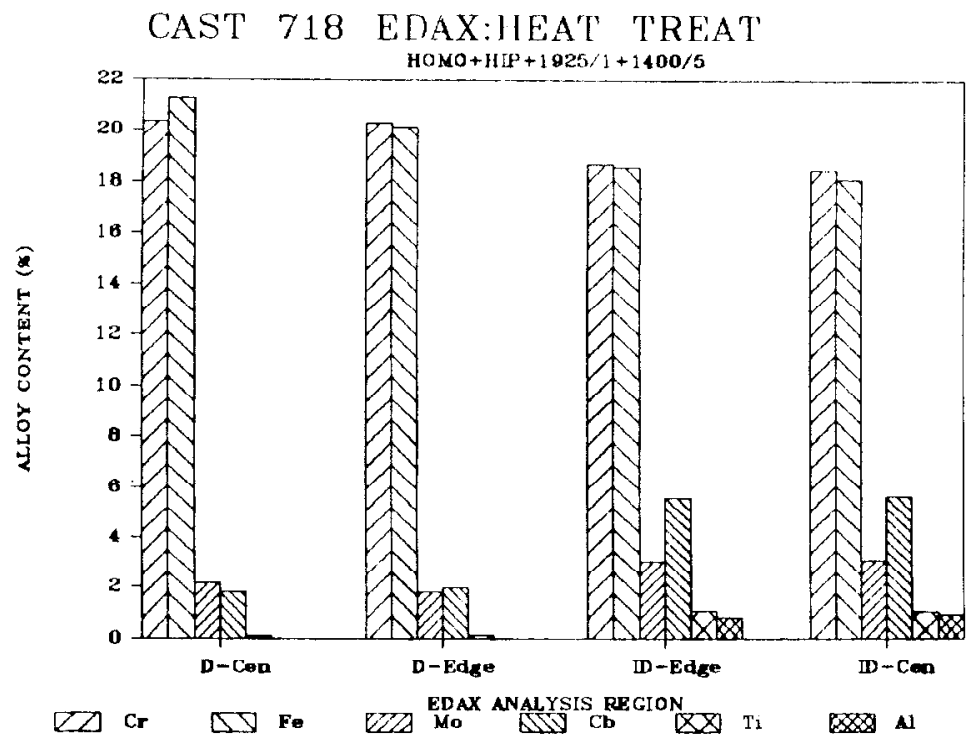

FIGURE 9, EDAX ANALYSIS OF DENDRIIIC AND INTEROENDRITIC REGIONS OF CAST 718 WITH $2000^{\circ} \mathrm{F} / 1$ HOUR + $2125^{\circ} \mathrm{F} / 4$ HOUR HIP + $1925^{\circ} \mathrm{F} / 1$ HOUR SOLUTION $+1400^{\circ} \mathrm{F} / 5$ HOUR AGE 


\section{Analytical Techniques}

This microstructural study of cast 718 required the use of microscopic, chemical, and $X$-ray techniques to Identify the solidification structures and phases formed during subsequent heat treatments. The use of the SEM to determine the $\mathrm{Cb}$ distribution in conjunction with the "Tag" technique provided an insight on the behavior of $c b$ with select temperature and time exposures. The "Tag" technique identified the Cb rich areas more easily than the chemical analysis by EDAX. This t:chnique is also being applied to studies of CD in wrought 718 materials.

\section{Correlation of Previous Microstructurai Results}

The phases found in this study of cast 718 agree with accepted phases found in wrought and powder metallurgy 718 materials. The higher temperature stability of the delta and Laves phases in cast 78 is attributed to the extensive segregation present in large sections of cast 718 components. Precipitation of delta, $Y^{\prime \prime}$, and $Y^{\prime}$ phases occurs readily during the slow cooling of the castings.

\section{Homogenization}

Certainly the segregation in the cast structure, if not fully homogenized, can be carried over into the wrought product. Previously published TTT diagrams show great varfations in the times and temperatures necessary for phase precipitation. This is undoubtably due to the presence of segregation in the starting materials.

Cast 718 which was given 120 hours at $2100^{\circ} \mathrm{F}$ still shows some inhomogeneity and total homogenization may be econonically impractical.

\section{Effect of cb Content on Precipitation}

Chemical analyses indicate that the stability of the various phases in cast 718 may depend on the range of the cb present. Some indications of these correlations are given below.

\begin{tabular}{ll} 
Phases & Range of $\mathrm{Cb}$ Content \\
\cline { 2 - 2 } & 108 \\
Delta & $8-10 \%$ \\
$Y^{\prime \prime}$ & $4-68$ \\
$Y^{\prime}$ & $2-48$
\end{tabular}




\section{REFERENCES}

1. J.F. Barker, "Effect of Casting Practices Upon Inconel $718 \mathrm{C}$ Properties and Microstructures" DM61-113, Apri1 13, 1961.

2. G.K. Bouse and P.W. Schilke, "Process Optimization of Cast Alloy 718 for Water Cooled Gas Turbine Application", TR8OMPL328, February 4, 1980.

3. G.K. Bouse and P.W. Schilke, "HTTT Metallurgical Support Investigations of Cast 718 - Final Report", TR8OMPL 335, August $21,1980$. 